\title{
The Effect of Vocabulary Knowledge on Chinese English Learners' Reading Comprehension
}

\author{
Tongqing $\mathrm{Gu}^{1}$ \\ ${ }^{1}$ School of Foreign Languages, Chengdu University of Information Technology, Chengdu, China \\ Correspondence: Tongqing Gu, School of Foreign Languages, Chengdu University of Information Technology, \\ Chengdu, Sichuan, 610225, China. E-mail: 915131080@qq.com
}

Received: February 20, 2017 Accepted: March 16, 2017 Online Published: July 15, 2017

doi:10.5539/ijel.v7n4p45 URL: http://doi.org/10.5539/ijel.v7n4p45

The research is financed by Sichuan Social Science Planning Fund Program (Project No. SC14WY18).

\begin{abstract}
Vocabulary knowledge is the foundation of English learning. This study, based on vocabulary knowledge frameworks, aims to further explore the effect of two dimensions of vocabulary knowledge i.e. breadth and depth of vocabulary knowledge, on two types of reading comprehension tasks, i.e., standard multiple choice question and summary writing in Chinese EFL context. 124 English majors in a Chinese university were randomly selected, and their vocabulary knowledge and reading comprehension ability were tested. The results of the study showed that both breadth and depth of vocabulary knowledge make contributions to reading comprehension; the breadth of vocabulary knowledge has a greater predictive power on multiple-choice reading comprehension than the depth of vocabulary, while vocabulary depth was the stronger predictor of post-reading summary writing. The results indicate that teachers need to attend to vocabulary knowledge and improve learners' reading ability by enhancing their vocabulary knowledge.
\end{abstract}

Keywords: breadth and depth of vocabulary knowledge, Chinese EFL context, standard multiple choice questions, summary writing

\section{Introduction}

Vocabulary knowledge plays an important part in second language learning. In the past decade, the relationship between vocabulary knowledge and reading comprehension has attracted the attention of many scholars (Li, 2003; Qian, 2002; Li, 2007; Li\& Kirby, 2014 etc.). However, previous studies are more concerned with the importance of vocabulary size in reading comprehension, while ignoring the role of vocabulary depth. In addition, there is room for improvement of the measures of vocabulary depth and reading comprehension. Consequently, to what extent the breadth and depth of vocabulary knowledge contribute to reading comprehension is far from clear.

Based on the previous studies, the measurement of depth of vocabulary in this study comprises word definition, multiple-meaning vocabulary and morphological awareness. Meanwhile, reading comprehension test includes literal or lower level and in-depth reading comprehension. By testing and analyzing the learners' vocabulary knowledge and reading ability, this study aims to further explore the effect of two dimensions of vocabulary knowledge i.e. breadth and depth of vocabulary knowledge, on two types of reading comprehension tasks, i.e., standard multiple choice questions and summary writing. It is hoped that the results can shed light on English teaching in an EFL context.

\section{Literature Review}

\subsection{Vocabulary Knowledge}

Over the years, the nature of vocabulary knowledge has been explored extensively (Cronbach, 1942; Richards, 1976; Nation, 1990, 2001; Qian, 1998, 2002). Among the studies, the frameworks of vocabulary knowledge proposed by Nation (2001) and Qian $(1998,2002)$ are considered to be more influential in the domain of L2 vocabulary research. 


\subsubsection{Nation's Conceptual Framework of Vocabulary Knowledge}

The framework of vocabulary knowledge proposed by Nation $(1990,2001)$ mainly focused on two questions: (a) what is a word? \& (b) what is involved in learning a word?

Table 1. Components of vocabulary knowledge (Nation, 2001, p. 27)

\begin{tabular}{|c|c|c|c|}
\hline \multirow[t]{6}{*}{ Form } & Spoken & $\mathrm{R}$ & What does the word sound like? \\
\hline & & $\mathrm{P}$ & How is the word pronounced? \\
\hline & Written & $\mathrm{R}$ & What does the word look like? \\
\hline & & $\mathrm{P}$ & How is the word written and spelled? \\
\hline & Word parts & $\mathrm{R}$ & What parts are recognizable in this word? \\
\hline & & $\mathrm{P}$ & What words parts are needed to express meaning? \\
\hline \multirow[t]{6}{*}{ Meaning } & Form and meaning & $\mathrm{R}$ & What meaning does this word form signal? \\
\hline & & $\mathrm{P}$ & What word form can be used to express this meaning? \\
\hline & Concepts & $\mathrm{R}$ & What is included in the concept? \\
\hline & references & $P$ & What items can the concept refer to? \\
\hline & Associations & $\mathrm{R}$ & What others words does this word make us think of? \\
\hline & & $\mathrm{P}$ & What other words could we use instead of this one? \\
\hline \multirow[t]{6}{*}{ Use } & Grammatical functions & $\mathrm{R}$ & In what patterns does the word occur? \\
\hline & & $\mathrm{P}$ & In what patterns must we use this word? \\
\hline & collocations & $\mathrm{R}$ & What words or types of word occur with this one? \\
\hline & & $\mathrm{P}$ & What words or types of words must we use with this one? \\
\hline & Constraints on use & $\mathrm{R}$ & Where, when and how often would we meet this word? \\
\hline & & $\mathrm{P}$ & Where, when and how often can we use this word? \\
\hline
\end{tabular}

Note. $\mathrm{R}=$ receptive, $\mathrm{P}=$ productive

As shown in Table 1, Nation's framework constitutes a set of 18 questions which were classified into three categories, and each includes receptive and productive aspects: (a) knowledge of form, which contains spoken \& written form and word parts; (b) knowledge of meaning, which consists of form and meaning, concepts \& references and associations; and (c) knowledge of use, which includes grammatical functions, collocations, and constraints on use, such as register and frequency.

This framework, defining vocabulary knowledge from the morphological, semantic and pragmatic perspectives, shows that all the aspects of vocabulary in this framework are closely interrelated. Meanings of words could be derived from the word form and context in which they are used. In the meantime, word forms and word meanings are also conductive to the improvement of vocabulary ability in real communication. However, Nation recognizes that this framework of vocabulary knowledge is actual an incomplete classification and there is still much room to improve in further research. For instance, it is difficult to measure language learners' vocabulary depth only through the description in his framework. And the categories in his framework are closely related to each other so it is hard to distinguish the specified words according to this classification.

\subsubsection{Qian's Framework of Vocabulary Knowledge}

Qian's conceptual framework of vocabulary knowledge (2002, p. 516) consists of four dimensions:

(a) Breadth of vocabulary knowledge or vocabulary size, which stands for the number of words that learners can recognize;

(b) Depth of vocabulary knowledge, which contains all word characteristics including pronunciation, word frequency, morphological or syntactic property, register, meaning, semantic feature and polysemy;

(c) Organization of lexicon, which stands for remembering the words, keeping the connection among the different words in learners' mind;

(d) Automaticity of receptive and productive knowledge, which refers to the whole basic process by which access to vocabulary knowledge is achieved from receptive and productive aspects respectively.

This framework emphasizes the importance of depth of vocabulary knowledge and accounts for vocabulary depth from psycholinguistic perspective. In his view, these four dimensions are connected and interact with each other. This framework is practical for researchers to explore what vocabulary knowledge is. To summarize, vocabulary knowledge includes three aspects: breadth of vocabulary knowledge, depth of vocabulary knowledge and use of vocabulary knowledge, and they interact with each other. 


\subsection{Studies on Vocabulary Knowledge and Reading Comprehension at Home and Abroad}

In first language research, it has been argued that vocabulary knowledge is an important predictor in reading comprehension (Anderson \& Freebody, 1981). However, to what extent the breadth and depth of vocabulary knowledge contribute to reading comprehension is not clear. Ouellette (2006) found that depth of vocabulary played a more important role in predicting reading comprehension than breadth of vocabulary. In contrast, Tannenbaum et al. (2006) argued that breadth of vocabulary had a stronger relationship to reading comprehension than vocabulary depth.

Similar to L1 studies, the relationship between vocabulary and reading comprehension was also explored in L2 (Koda 1989; Laufer 1992, 1996; Nation 2001; Proctor et al., 2005). Laufer $(1992,1996)$ conducted two studies on the relationship between breadth of vocabulary and reading comprehension. The correlation of the first study is .50 , and the other is .71 which means there are correlations between breadth of vocabulary and reading comprehension.

Qian (2002) conducted a research to verify the effect of vocabulary size and depth of vocabulary on reading comprehension in academic reading. He measured depth of vocabulary from three aspects (synonymy, polysemy and collocation), and the results of the study showed both the vocabulary size and depth of vocabulary have a great impact on reading comprehension.

In China, Li (2003) examined the relationship between the depth of vocabulary knowledge and reading comprehension. 56 third-year non-English majors participated in vocabulary knowledge test and reading comprehension test. The result of the research showed that there is a close relationship between breadth of vocabulary and reading comprehension. In other words, learners with large vocabulary size usually had stronger reading ability. And the study also found that the accuracy of vocabulary knowledge had little effect on reading comprehension.

Liu (2002) explored the relationship among vocabulary size, depth of vocabulary knowledge and English reading ability. She found that vocabulary size could predict only $32.1 \%$ of reading comprehension. And vocabulary size is moderately related to depth of vocabulary knowledge. With the growth of vocabulary size, vocabulary depth at the sentence and textual level also increased, but the correlation between them is weak. Lu didn't explore to what extent depth of vocabulary knowledge can predict reading comprehension,

In summary, previous studies are inconsistent in terms of the contribution of vocabulary knowledge to reading comprehension, and the measures of the key constructs also need improving. So it is still worth exploring the effect of breadth and depth of vocabulary knowledge on reading comprehension because of the complexity and multidimensional nature of vocabulary knowledge and reading comprehension.

\section{Research Design}

\subsection{Research Questions}

The present study, as noted above, investigates the effect of two types of vocabulary knowledge on Chinese EFL learners' reading comprehension. Specifically, the study aims to answer the following research questions:

(a) What is the relationship between the breadth and depth of vocabulary knowledge and reading comprehension?

(b) To what extent does breadth and depth of vocabulary knowledge contribute to standard multiple-choice reading comprehension?

(c) To what extent does breadth and depth of vocabulary knowledge contribute to post-reading summary writing?

\subsection{Research Subjects}

124 sophomores who major in English in a university in Sichuan province were randomly selected from 11 classes. The participants consist of 15 male students and 109 female students, and their age ranges from 18 to 20 . The gender unbalance is due to the better performance of females on the college matriculation exam that the school used to recruit students. The participants voluntarily participated in the study and the tests were administered two months after they took part in the TEM-4 (Test of English Majors, Band 4).

\subsection{Research Instruments}

\subsubsection{Measurement of Breadth of Vocabulary Knowledge}

Schmitt \& Clapham's vocabulary level test (2001) was administered to measure students' breadth of vocabulary. It comprises five different vocabulary levels, namely, the 2,000, 3,000, 5,000, 10,000 and academic vocabulary. For each part, there are ten groups of words and each group contains six written forms of words and three 
meanings. Considering the English level of the participants, the 10,000 vocabulary level was eliminated. The students were asked to choose the right word to go with each meaning and write the number of that word next to its meaning. The test was finished within 45 minutes. Dictionaries and references books were not allowed to use during the process of testing. The score was the number of correct answers selected, with a total score of 120 .

\subsubsection{Measurements of Depth of Vocabulary Knowledge}

The depth of vocabulary knowledge was measured by word definition, multiple-meaning vocabulary and morphological awareness.

\section{(a) Word definition}

This subtest was based on Ouellette's (2006) measure to assess students' depth of vocabulary. 10 high frequency words were chosen as the target words from the lexicons for TEM-4. Concordance search found that the frequency of the selected target words is above 5000 per million in the Corpus of Contemporary American English (COCA, 1990-2015). Subjects were asked to provide definitions for each target word in written form, and the definitions should involve four features, i.e. category, function, description and value. Instructions together with an example were given to the students on the test paper. For example, the definition of the word 'milk' could involve information about category, e.g. drink, function, e.g. can be drunk, description, e.g. white liquid, produced by cows, goats, and value, e.g. good for health. One point was given for each feature, to a maximum of 4 points per word; the total score of the subtest was 40 .

(b) Multiple-meaning vocabulary

This test, based on Qian's (2002) depth of vocabulary knowledge measure and Tannenbaum et al.'s (2006) multiple meaning test, was administered to measure students' knowledge of polysemy. There were 15 target words chosen from the high frequency words of TEM-4. Concordance search found that the frequency of these words is above 5000 per million in the COCA (ibid). And each word was presented in four different sentence contexts. Students were asked to choose the sentences in which the target word was used correctly. For example, for the target word 'reply', the sentence contexts were: (a) Please reply me as early as possible. (b) I replied to his letter a week ago. (c) I called out a challenge, but there was no reply. (d) The reply of the water is very cold. The right answers are $b$ and $c$. The number of correct sentences per word varied from 0 to 4 . The score was the number of correct answers selected, with a maximum total score of 30 .

(c) Morphological awareness

Based on the study of Bowers \& Kirby (2010), this test was designed to test students' ability to recognize the bases in multi-morphemic words presented in written form. In this section there were 30 words chosen from the lexicons of TEM-4. Each word has the stem plus a prefix and/or a suffix and the subjects are required to identify the base of a given word The score was 2 for circling the smallest base, 1 for circling any word which removed at least one affix but did not identify the smallest base, and 0 for any other response. For example, in the word 'starring', 0 point was given for ring which is not the base of the word, 1 point for circling starr because the students accurately peeled off a suffix ing, and 2 points for circling star which is the base of "starring". The maximum total score of this test was 60 .

\subsubsection{Measurements of Reading Comprehension}

There are two measures of reading comprehension in this study. The standard multiple-choice reading comprehension format was designed to measure students' basic ability of reading, i.e., the students can read a passage independently to quickly locate factual information in it. In view of the participants' current English level, 4 passages were chosen from TEM-4. There are 20 multiple choice questions, and the students were asked to finish the test within 30 minutes. Each correct answer would be awarded one point, and the total score was 20 .

Summary writing, which is based on Kirby et al. (2012), was administered to measure students' in-depth text understanding. To guarantee the validity, a text from the reading passage of TEM-4 was chosen. The students were given 30 minutes to read the passage and to summarize the main idea of each paragraph in their own words and write a summary of the passage in English. The students' summaries were scored for the number of main ideas, that is, those which require the reader to integrate the thematic content or the main ideas of the text. The text was analyzed to have five main idea units and the total score was 20 .

\subsection{Data Collection and Analysis}

Data were collected from the three tests: breadth of vocabulary knowledge test, depth of vocabulary knowledge tests and reading comprehension tests. The tests were administered in normal class time and two teachers were engaged in the testing work to ensure that the participants would treat them seriously. Dictionaries and reference 
books were unavailable to the students during the process of testing and discussion was not allowed. The vocabulary test papers and multiple choice reading comprehension test from 124 participants were scored manually by the researcher. 30 summary writings were randomly chosen by the researcher and scored by two raters in order to ensure the reliability of the results. And the inter-rater reliability was .959 .

The Pearson correlation analysis was used to analyze the correlation between vocabulary knowledge and reading comprehension, and stepwise regression analysis was adopted to analyze the effect of two types of vocabulary knowledge on two reading comprehension tasks. Reading comprehension will be used as the dependent variable, while breadth and depth of vocabulary knowledge will be considered as independent variables respectively.

\section{Results and Discussion}

In this section, the analysis focuses on the effect of two types of vocabulary knowledge on two reading comprehension tasks to answer the research questions outlined above.

\subsection{The Correlation between Vocabulary Knowledge and Reading Comprehension Ability}

Table 2. Correlations between vocabulary knowledge and reading comprehension

\begin{tabular}{llll}
\hline Tests & & Multiple choice & Summary writing \\
\hline \multirow{3}{*}{ breadth of vocabulary } & Pearson Correlation & $.277^{* *}$ & $.275^{* *}$ \\
& Sig. (2-tailed) & .002 & .002 \\
& $\mathrm{~N}$ & 124 & 124 \\
word definition & Pearson Correlation & -.108 & .072 \\
& Sig. (2-tailed) & .234 & .424 \\
& $\mathrm{~N}$ & 124 & 124 \\
multiple-meaning vocabulary & Pearson Correlation & .054 & .113 \\
& Sig. (2-tailed) & .553 & .211 \\
& $\mathrm{~N}$ & 124 & 124 \\
morphological awareness & Pearson Correlation & $.234^{* *}$ & $.356^{* *}$ \\
& Sig. (2-tailed) & .009 & .000 \\
& $\mathrm{~N}$ & 124 & 124 \\
\hline
\end{tabular}

Note. $\mathrm{N}=124 *=P<0.05, * *=P<0.01 ; * *$ Correlation is significant at the 0.01 level (2-tailed).

Table 2 indicates that the correlation coefficient between vocabulary size and reading comprehension is .277 $(p<0.01)$, between vocabulary size and summary writing is $.275(p<0.01)$. Correlation coefficients of the two variables are between .20 and .40 which means a moderate positive correlation between breadth of vocabulary and reading comprehension. The correlation coefficient between morphological awareness and reading comprehension is $.234(p<0.01)$, between morphological awareness and summary writing is $.356(p<0.01)$. Correlation coefficients of the two variables are between .20 and .40 which also means a positive correlation between morphological awareness and reading comprehension. Thus, it is clear that both breadth and depth of vocabulary play a role in two types of reading comprehension, with morphological awareness being the main contributing factor.

Based on the results of correlation analysis, stepwise regression analysis was used to analyze the extent to which the breadth and depth of vocabulary knowledge contributes to predict students' performance in standard multiple-choice reading comprehension and summary writing. During data processing, the scores of multiple-choice questions and summary writing were respectively used as dependent variables and the scores of breadth and depth of vocabulary knowledge were used as independent variables.

\subsection{The Effect of Vocabulary Knowledge on Multiple Choice Reading Comprehension}

Table 3. Results of model summary on breadth \& depth of vocabulary knowledge and multiple-choice reading comprehension

\begin{tabular}{lllll}
\hline Model & $\mathrm{R}$ & R Square & Adjusted R Square & Std. Error of the Estimate \\
\hline 1 & $.677^{\mathrm{a}}$ & .477 & .469 & 2.40898 \\
2 & $.741^{\mathrm{b}}$ & .517 & .502 & 2.36613 \\
\hline
\end{tabular}

Note. a. Predictors: (Constant), breadth of vocabulary; b. Predictors: (Constant), breadth of vocabulary, morphological awareness. 
As shown in Table 3, the model of the correlation coefficient is .741, determination coefficient is .517 , and after adjusting decision coefficient is 0.502 , which demonstrates that the interpretation degree of the selected independent variable is more than $50 \%$. When $\mathrm{R}$ square is close to 1 , it indicates the higher reference value of the model. The breadth of vocabulary knowledge can explain $46.9 \%$ of the variance in the dependent variable by itself. And the breadth of vocabulary and morphological awareness together can explain $50.2 \%$ of the variance in the dependent variable. In Table 2, we can see that the correlation coefficient between vocabulary size and multiple-choice reading comprehension is .277, and the correlation coefficient between morphological awareness and multiple-choice reading comprehension is .234. From this descriptive statistics, we think that the breadth of vocabulary knowledge has a greater predictive power on multiple-choice reading comprehension than the depth of vocabulary. The finding is similar to Li \& Kirby (2014) who claimed that breadth of vocabulary is more related to the Gates-MacGinitie reading comprehension test, which poses multiple choice questions after short passages. Generally speaking, learners with a large vocabulary size are able to get higher score when doing multiple choice reading comprehension.

Table 4. Stepwise regression analysis results of scores of multiple-choice reading comprehension as dependent variables

\begin{tabular}{|c|c|c|c|c|c|c|c|c|}
\hline \multirow[t]{2}{*}{ Model } & & \multicolumn{2}{|c|}{ Unstandardized Coefficients } & \multirow{2}{*}{$\begin{array}{l}\text { Standardized } \\
\text { Coefficients } \\
\text { Beta }\end{array}$} & \multirow[t]{2}{*}{$\mathrm{t}$} & \multirow[t]{2}{*}{ Sig. } & \multicolumn{2}{|c|}{ Collinearity Statistics } \\
\hline & & $\mathrm{B}$ & Std. Error & & & & Tolerance & VIF \\
\hline \multirow{2}{*}{1} & (Constant) & 6.777 & 1.979 & & 3.424 & .001 & & \\
\hline & breadth of vocabulary & .064 & .020 & .277 & 3.183 & .002 & 1.000 & 1.000 \\
\hline \multirow{3}{*}{2} & (Constant) & 6.264 & 1.956 & & 3.202 & .002 & & \\
\hline & breadth of vocabulary & .058 & .020 & .251 & 2.913 & .004 & .983 & 1.017 \\
\hline & morphological awareness & .033 & .014 & .201 & 2.336 & .021 & .983 & 1.017 \\
\hline
\end{tabular}

Dependent variable: reading comprehension

When the score of standard multiple-choice reading comprehension is used as dependent variable and the scores on breadth of vocabulary and morphological awareness are used as independent variables, the results of stepwise regression analysis (shown in Table 4) show that the regression coefficient values of the breadth of vocabulary, morphological awareness are .058 and .033 , $\mathrm{T}$ value is 2.913 and $2.336(p<.05)$. That means there is significant statistical significance. Therefore, the breadth of vocabulary and morphological awareness both have positive effects on multiple-choice reading comprehension.

\subsection{The Effect of Vocabulary Knowledge on Summary Writing}

In this part, stepwise regression analysis was used to explore the effect of vocabulary knowledge on post-reading summary writing. Summary writing was considered as dependent variable and breadth of vocabulary, word definition, multiple-meaning vocabulary, morphological awareness as independent variables. Since morphological awareness is more related to multiple-choice reading comprehension, it is conducted as the main independent variable.

Table 5. Results of model summary on breadth and depth of vocabulary knowledge and summary writing

\begin{tabular}{clccc}
\hline Model & R & R Square & Adjusted R Square & Std. Error of the Estimate \\
\hline 1 & $.656^{\mathrm{a}}$ & .427 & .420 & 5.11432 \\
2 & $.725^{\mathrm{b}}$ & .480 & .467 & 4.97597 \\
\hline
\end{tabular}

Note. a. Predictors: (Constant), morphological awareness. b. Predictors: (Constant), morphological awareness, breadth of vocabulary.

As shown in Table 5, the model of the correlation coefficient is .725 , determination coefficient is .480 , after adjusting decision coefficient is .467 , which demonstrates that the interpretation degree of the selected independent variable is $46.7 \%$. Morphological awareness can explain $42 \%$ of the variance of summary writing, while breadth of vocabulary together with morphological awareness can explain $46.7 \%$ of the variance of summary writing. However, in Table 2, the correlation coefficient between breadth of vocabulary and summary writing is .275 , and that between morphological awareness and summary writing is .356 . From this descriptive 
statistics, we think that morphological awareness, one of the components of vocabulary depth, has a greater predictive power on summary writing than the breadth of vocabulary.

Table 6. Stepwise regression analysis results of scores on summary writing as dependent variables

\begin{tabular}{|c|c|c|c|c|c|c|c|}
\hline \multirow[t]{2}{*}{ Model } & \multicolumn{2}{|c|}{ Unstandardized Coefficients } & \multirow{2}{*}{$\begin{array}{l}\text { Standardized } \\
\text { Coefficients } \\
\text { Beta }\end{array}$} & \multirow[t]{2}{*}{$\mathrm{t}$} & \multirow[t]{2}{*}{ Sig. } & \multicolumn{2}{|c|}{ Collinearity Statistics } \\
\hline & $\mathrm{B}$ & Std. Error & & & & Tolerance & VIF \\
\hline \multirow{3}{*}{$\begin{array}{ll}1 & \text { (Constant) } \\
\text { morphological awareness } \\
\text { (Constant) }\end{array}$} & 8.130 & 1.108 & & 7.336 & .000 & & \\
\hline & .128 & .030 & .356 & 4.212 & .000 & 1.000 & 1.000 \\
\hline & -3.015 & 4.114 & & -.733 & .465 & & \\
\hline \multirow{2}{*}{$\begin{array}{l}2 \text { morphological awareness } \\
\text { breadth of vocabulary }\end{array}$} & .117 & .030 & .326 & 3.932 & .000 & .983 & 1.017 \\
\hline & .117 & .042 & .233 & 2.807 & .006 & .983 & 1.017 \\
\hline
\end{tabular}

Note. a. Dependent variable: summary writing.

As shown in Table 6, stepwise regression results when summary writing was used as dependent variable, shows that the regression coefficient values of the breadth of vocabulary, morphological awareness are both .117, T values are 2.807 and 3.932, while the $P$ value is less than 0.05 . This indicates that there is a significant statistical significance. So the breadth of vocabulary and the morphological awareness have a positive effect on summary writing. That is, students with higher scores in the tests of breadth of vocabulary and morphological awareness can also get higher scores in summary writing. And the corresponding $\mathrm{P}$ values of the other variables are more than 0.05 , which indicates there is no statistical significance between them. So it demonstrates that the rest variables have less significant effect on summary writing.

\section{Conclusion and Implications}

The present study found that vocabulary knowledge and English reading comprehension are positively correlated with each other. In second language acquisition, breadth and depth, as two primary dimensions of vocabulary knowledge, are both significant predictors for different aspects of reading comprehension. Breadth of vocabulary knowledge, which is more closely related to reading comprehension than the depth of vocabulary knowledge, can contribute more to the prediction of multiple-choice reading comprehension. In contrast, depth of vocabulary knowledge is the stronger predictor of summary writing.

In the light of the major findings of this study, some pedagogical implications for EFL teaching and learning are proposed. One important implication for English teaching is that vocabulary teaching activities should involve much more than simply introducing the form and superficial meanings of words. The high frequency words (for example, words in the GSL) should be taught in more detail so that learners can acquire full knowledge of the core vocabulary. Both teachers and students need to focus on at least three aspects of vocabulary knowledge, i.e., form (both spoken and written), meaning, including definition, synonymy, polysemy, and use which includes collocation, morphological, syntactical and pragmatic properties. Teachers are recommended to use more teaching strategies in the teaching process to help EFL learners acquire both breadth and depth of vocabulary knowledge. In addition, vocabulary learning strategies need to be introduced and practiced so that students can become more independent and autonomous learners. Currently, there are rich online resources like vocabulary learning websites and English corpora which can be useful supplements for vocabulary teaching. When necessary, vocabulary exercises and vocabulary tests can be used to enhance students' vocabulary learning.

On the part of the English learners, they should balance their acquisition of both breadth and depth of vocabulary knowledge. The vocabulary tests show that the learners' acquisition of depth of vocabulary knowledge is slower than that of vocabulary breadth. Chinese EFL learners should attach importance to both quantity and quality of English words acquired. To increase the depth of vocabulary knowledge, English learners are recommended to use bilingual English learning dictionaries which provide more detailed and comprehensive information of English words than wordlists. Vocabulary learning strategies such as keeping a vocabulary notebook, spaced review, using dictionary can be employed in the course of vocabulary learning. Second language learners generally undergo four stages (from high to low) in their vocabulary development: active recall, passive recall, active recognition and passive recognition. The vocabulary level of the English learners in this study is roughly at the recognition stage. It is therefore imperative that Chinese EFL learners improve their vocabulary knowledge by using a variety of methods and strategies. 
Above all, in order to develop students' reading ability, it is worth arousing teachers and students' awareness of the significance of vocabulary knowledge, especially the depth of vocabulary knowledge, and other factors influencing reading comprehension. And the impact of vocabulary knowledge on different types of reading comprehension tasks, such as blank filling, making judgment and answering question can be further investigated in future studies.

\section{References}

Cronbach, L. J. (1942). An analysis of techniques for diagnostic vocabulary testing. Journal of Educational Research, 36, 206-217. https://doi.org/10.1080/00220671.1942.10881160

Kirby, J. R., Cain, K., \& White, B. (2012). Deeper learning in reading comprehension. In J. R. Kirby \& M. J. Lawson (Eds.), Enhancing the quality of learning: Dispositions, instruction, and learning processes (pp. 315-338). Cambridge: Cambridge University Press. https://doi.org/10.1017/cbo9781139048224.018

Laufer, B. (1992). How much lexis is necessary for reading comprehension? In H. Be'joint \& P. Arnaud (Eds.), Vocabulary and applied linguistics (pp. 126-32). MacMillan. https://doi.org/10.1007/978-1-349-12396-4_12

Nation, I. S. P. (1990). Teaching and learning vocabulary. New York: Newbury House.

Nation, I. S. P. (2001). Learning vocabulary in another language. Cambridge: Cambridge University Press. https://doi.org/10.1017/CBO9781139524759

Ouellette, G. P. (2006). What's meaning got to do with it: The role of vocabulary in word reading and reading $\begin{array}{llll}\text { comprehension. Journal of Educational Psychology, 98, 566. } & \text { 554 }\end{array}$ https://doi.org/10.1037/0022-0663.98.3.554

Qian, D. D. (1998). Depth of vocabulary knowledge: Assessing its role in adults' reading comprehension in English as a second language. (Unpublished doctoral dissertation). University of Toronto, Toronto, ON.

Qian, D. D. (1999). Assessing the roles of depth and breadth of vocabulary knowledge in reading comprehension. The Canadian Modern Language Review, 56, 282-308. https://doi.org/10.3138/cmlr.56.2.282

Qian, D. D. (2002). Investigating the relationship between vocabulary knowledge and academic reading performance: An assessment perspective. Language Learning, 52, 513-536. https://doi.org/10.1111/1467-9922.00193

Read, J. (1993). The development of a new measure of L2 vocabulary knowledge. Language Testing, 10, 355-371. https://doi.org/10.1177/026553229301000308.

Read, J. (2000). Assessing vocabulary. Cambridge: Cambridge University Press. https://doi.org/10.1017/CBO9780511732942

Schmitt, N., Schmitt, D., \& Clapham, C. (2001). Developing and exploring the behavior of two new versions of the vocabulary levels test. Language Testing, 18, 55-88. https://doi.org/10.1191/026553201668475857

Tannenbaum, K., Torgesen, J. K. \& Wagner, R. K. (2006). Relationships between word knowledge and reading comprehension in third-grade children. Scientific Studies of Reading, 10, 381-398. https://doi.org/10.1207/s1532799xssr1004_3

\section{Appendix}

\section{The depth of vocabulary test}

(a) Word Definition

Please define the words from the following four features: category, function, description and value. One point will be given for each feature. (Note. There is a picture under each word to help define it. To save space, the pictures were deleted here.)

For example: apple

Category: fruit

Function: can be eaten

Description: different colors; round shape; has skin and seeds; sour and sweet; grows on trees

Value: good for health; gives vitamin C 
1). coach

2). fence

3). handle

4). cotton

5). leather

6). vessel

7). label

8). helicopter

9). cottage

10). cabinet

(b) Multiple-meaning Vocabulary

In this section, there are fifteen target words and each word is presented in four different sentence contexts. Please choose the sentences in which the target word is used correctly.

1). agent

An agent is a government organization responsible for a certain area of administration.

Get me my agent on the phone!

In the reaction, the fraction acts as an agent.

We always regard him as a friend, but he showed his colors in the current agent.

2). budget

We couldn't budget for every emergency.

She budgets an English dictionary for me.

For budget reasons, the company will reduce the staffs.

The fruit is budget for him.

3). transport

Ordinary people got to stick to public transport.

I can transport the messages for her.

We reduce the traffic required to transport staff and customers to these locations.

Communication is the transport of information from one person to another.

4). preserve

He showed great preserve by staying in the job.

This land is protected as a wildlife preserve.

We will do everything to preserve peace.

Risks are preserved differently by different people.

5). extreme

It has no effect on this data extreme.

This extreme view hasn't captured popular opinion.

As an extreme example, imagine what would happen if you were to store water in a lead container.

Plants are the extreme source of all foodstuffs.

6). appeal

When night falls, stars appeal.

An appeal is being made for help for those who lost their homes in the earthquake.

On the other hand, the idea appealed to him.

He can appeal, but legal experts say they do not expect the ruling to be overturned. 
7). torture

Run like a torture.

No torture would make him talk.

Suddenly somebody flashed an electric torture.

Despite being tortured she proclaimed her innocence.

8). delay

A man came to delay the carpet.

If he delayed any longer, the sun would be up.

The courts delay with those who break the law.

They claimed that such a delay wouldn't hurt anyone.

9). ruin

My wife was ruining her health through worry.

They lived under foreign ruin for many years.

The Building was in ruins.

One dead child was found in the ruins almost two hours after the explosion.

10). ultimate

He said it is still not possible to predict the ultimate outcome.

Creativity and ultimate often depends on how well you hide your sources.

Ballet is the ultimate in human movement.

The people are living in ultimate poverty.

11). casual

I also bought some casual clothes for the weekend.

She has to get a casual work to subsist.

It's difficult for me to be casual about anything.

He lives for nothing but his casual.

12). trap

She has just trap an interview.

The train was trapped underground by a fire.

She turned off the trap and dried her hands.

His offer smelt of a clear trap.

13). adopt

$\mathrm{He}$ is the person who adopts the stories for television.

There are hundreds of people desperate to adopt a child.

I disapproved strongly of his adopt.

If you think our suggestions work for you, then adopt them.

14). scale

He underestimates the scale of the problem.

Let me menu the travel scale for next week.

The scale of the map is 1: 460000 .

The patient rates the therapies on a scale of zero to ten.

15). academic

There is a middle school attached to the academic. 
I finished academic and live far away from her.

Their academic standards are high.

A group of academics say they can predict house prices through a computer program.

(c) Morphological Awareness

In this section there are thirty words. Please circle the smallest part, that is, the base, which is related to the main word in meaning. The scoring was 2 for circling the smallest base, 1 for circling any word which removed at least one affix but did not identify the smallest base, and 0 for any other response.
1. consciousness
2. description
3. accompanying
4.climber
5. activate
6. subsequent
7. ambition
8. disapproval
9. flexibility
10. acknowledgement
11. industrious
12. immediately
13. responsible
14. justify
15. remarkable
16. mechanism
17. succession
18. considerable
19. potential
20. optimistic
21. negative
22. available
23. commandment
24. accountant
25. manufacturer
26. substantial
27 . permanently
28. principles
29. revival
30 . suspicious

\section{Copyrights}

Copyright for this article is retained by the author(s), with first publication rights granted to the journal.

This is an open-access article distributed under the terms and conditions of the Creative Commons Attribution license (http://creativecommons.org/licenses/by/4.0/). 